\title{
Preface
}

\section{For the "Special Issue on The 37th Annual Meeting of Japanese Society of Biorheology"}

We are very glad to publish the Special Issue on The 37th Annual Meeting of Japanese Society of Biorheology (June 5 6, 2014, Omiya, Saitama, Japan). The meeting was held jointly with The 1st Annual Meeting of Cardiovascular Stroke Society of Japan (CVSS) and involved 65 oral presentations, including 2 invited talks in Research Forum Session, 2 invited talks in Society Awards Session and 5 talks in Joint Session with CVSS, and 26 poster presentations. The program of this two-day meeting was prepared providing the 7 Organized Sessions that the Society has been focusing on as strategic research areas for the last few years. The meeting was definitely successful and much appreciated by the attendees.

As original articles, this special issue consists of 5 excellent papers contributed by the attendees to the meeting. We believe that this special issue could be a platform for an exchange of ideas and concepts as a follow-up activity of the conference.

During the meeting, the Oka Shoten Prize was awarded to Prof. Nobuji Maeda (Emeritus Professor, Ehime University, Japan) for his outstanding contribution in the field of Biorheology. This special issue also includes an essay by Prof. Maeda at the occasion of the prize.

Finally, we would like to express profound gratitude to all the authors and reviewers for their wonderful contributions to this special issue, and the editorial board members for their continuous support to this journal.

\section{Guest Editor}

Marie OSHIMA, PhD, Professor

The University of Tokyo, Japan

Editor-in-Chief

Toshiro OHASHI, PhD, Professor

Hokkaido University, Japan 